\title{
Opuntia ficus-indica as Nutritious Food Ingredient; Prevalence for Therapeutic Speciality
}

\author{
Saniya Ramzan ${ }^{1, *}$, Maryam Saeed ${ }^{2}$ \\ ${ }^{1}$ National Institute of Food Science and Technology, University of Agriculture, Faisalabad, Pakistan. \\ ${ }^{2}$ Institute of Agricultural Sciences, University of the Punjab, Lahore, Pakistan.
}

\section{ABSTRACT}

Background: It is predicted that the world's population, specifically in arid and semi-arid regions, usually with complications such as water scarcity, climate change, soil erosion, and wind erosion, is facing food insecurity issue. Moreover, the outbreak of several diseases is further a burden on the people living in such areas. The growth of improved crop varieties which is compatible with agroclimatic conditions of the site such as Opuntia ficus-indica is the ray of hope. Multipurpose native crops like Opuntia ficus-indica is cultivated owing to it is drought tolerant ability and growth in different ranges of the environment. Furthermore, it has natural components that can not only be served as food but also the therapeutic ability for numerous diseases.

Objectives: The purpose of this review is concerning global issues such as food insecurity, malnutrition and their solution through natural products i.e. nutraceuticals. The target is to find one of the numerous approaches that can be adapted to focus on dealing with such problems.

Methodology: Opuntia ficus-indica has various nutraceutical uses that had been utilized in past but can further be accommodated for commercial utilization and public benefit. In this review, the therapeutic aspects of Opuntia ficus-indica have been elaborated with the utilization of its components to fight different diseases. Different studies from various scientists published in the form of research/review articles have been overviewed proving its physico-chemical elements to be beneficial in this aspect.

Results: Opuntia ficus-indica is not only a source of food but also has exponential components that serve as nutraceuticals including phytochemicals such as phenolics, vitamin C, flavonoids, betalains, and carotenoids. These components impart diverse beneficial effects on health and act as anti-ulcerogenic, anti-carcinogenic, antioxidant, hepatoprotective, anti-atherogenic, and immunomodulator.

Conclusion: Opuntia ficus-indica is a miracle of nature that has been bestowed upon us to reduce the risk of many calamities. It can not only be served as food but also imparts beneficial effects on health that not only reduces the chances of getting sick but also helps in alleviating the drastic effects of disease exposure.

$\begin{array}{lcl}\text { Keywords } & \text { *Address of Correspondence } & \text { Article info. } \\ \text { Antioxidant, Apoptosis, Hepatotoxicity, } & \text { saniyaramzan8@gmail.com } & \text { Received: August 14, 2020 } \\ \text { Fortified, Extract. } & & \text { Accepted: November 24, 2020 }\end{array}$

Cite this article: Ramzan S, Saeed M. Opuntia ficus-indica as Nutritious Food Ingredient;

Prevalence for Therapeutic Speciality. RADS J Biol Res Appl Sci. 2020; 11(2):144-153.

This is an Open Access article distributed under the terms of the Creative Commons Attribution License (http://creativecommons.org/licenses/by/4.0), which permits unrestricted use, distribution, and reproduction in any medium provided the original work is properly cited.

\section{INTRODUCTION}

Cacti (singular Cactus) have unique and unusual properties that are adaptive to extremely hot and arid/semi-arid environments. They show a variety of functional and structural characteristics which make them more interesting like water conservation and drought tolerance capabilities. As for drought tolerance ability, it comes from the phenomenon of $\mathrm{CO}_{2}$ fixation capacity (CAM). Moreover, its leaves have the shape of spines, while the stem is transformed into the succulent structure containing chlorophyll ${ }^{1}$. Commonly, it is native to North 
America, Venezuela, Bolivia, South Africa, Argentina, Jordan, Israel, and West Indies, but now it is commonly growing in India, Italy, Spain, Mexico, Northern Africa, and the USA where they are now a significant part of people's dietary needs. It can be found in range of the environment from the dessert area below sea level to high altitude areas such as mountains of Peru². The genus Opuntia has approximately 300 different species which produces edible fruit varieties but the most important of these are Opuntia ficus indca, Opuntia robusta, Opuntia streptocantha, O. amyclaea, Opuntia. megacantha, O.hiptiacantha, and Opuntia ficus indica (L) Mill. In different countries, a cactus pear is cultivated for different purposes e.g. to ensure food security (control the wind, water, and soil erosion, utilize as forage and as fence), use in the food processing industry (natural colorant, juice, jam, vinegar, flour, and food supplement), as a pharmaceutical product (essential oils, herbal extracts, in medicine), and in cosmetic industry (seed oil, soap, and shampoo) $)^{3}$.

Opuntia ficus-indica (L.) Mill., common name: prickly pear/nopal cactus, family: Cactaceae (dicotyledonous angiosperm) is an important cactus species in agriculture of non-irrigated lands due to its utility in food, fodder, dye, source of energy, ecosystem remediation, and prevention of soil erosion 4 . It is also recognized as "fruit for the poor", "treasure under spines", "future plant", "scared plant" and "monster tree" and these names depict its significance in human life ${ }^{5}$. The largest producer of Opuntia ficus-indica species in Mexico with 72000 hectare (ha) area under fruit cultivation and 10,500 for nopalitos. In Brazil, North African countries (Morocco, Egypt, Tunisia, Algeria, and Libya) Italy, and Chile, the area under cultivation is 40000ha, 16000ha, 2500ha and 1100ha respectively6,7. Without any technical involvements, the crop is produced in two seasons per year i.e. February-April and JulySeptember with the covered area of 934.4ha in Chile. Among African Countries i.e. Algeria, Ethiopia, Morocco, South Africa, Tunisia where Optunia species are grown, Ethiopia is the largest producer of cactus pear with the covered area of 360,000ha. The major purposes of its cultivation are fencing, delicious fruit, essential oil, pharmaceutical products, food products, cosmetics, livestock feed, and forage ${ }^{8}$. It is a cheap source of food i.e., nopal/cladodes and prickly pear, fodder, and ornamental use. Cladodes are used as salads. Prickly pear is an elongated and fleshy berry having different sizes, color, and shape which can be consumed in the fresh, dried, and preserved form such as syrups, jams and candy-like products 9 . In most of the West Asian countries, the cactus is established for food and feed production, also utilized as hedges around the houses for enhancing aesthetic value. The modern cactus pear production in Australia is very small around 200ha and most established in the home gardens. Among the European countries, Italy is famous for its appreciation of Opuntia ficus-indica and it was recognized as "bread for poor" and also being used as an emergency fodder. Portugal has also promoted the production of cactus pear and planned to plant on more than 500ha which was before 200ha and also made the plan to engage the unemployed persons ${ }^{2}$.

Opuntia ficus-indica contains $92 \%$ moisture in addition to $4-6 \%$ total fiber and $1-2 \%$ protein $^{10}$. It is of great nutritional profile having high sugars i.e., glucose, fructose, and sucrose, other macronutrients like protein, lipid, ash, fiber, and minerals. Moreover, there is an increased amount of free amino acids including glutamine, proline, serine, methionine, arginine, aminobutyric acid, and histidine. There is considerable amount of bioactive compounds available in Opuntia ficus-indica for example ascorbic acid, carotenoids, and taurine ${ }^{11,12}$. It is known to have pigments and molecules which are usable in nutritive and medicinal aspects that make it among the list of functional foods ${ }^{13}$. These pigments can be classified according to the chromophore structure such as chromophores with conjugated systems i.e. carotenoids, caramel, betalains, lakes, and synthetic pigments, and metal coordinated porphyrins such as chlorophyll and myoglobin. The amount of bioactive compounds in the pulp of cactus pear varies with the variety and place of growth ${ }^{14}$.

\section{THERAPEUTIC PROPERTIES}

\section{Anti-oxidant Activity}

The oxidation process in the body is the stimulant of various diseases. Polyphenols present in Opuntia ficusindica possesses anti-oxidant activity which is divided into flavonoids, stilbenes, phenolic acids, and lignin \& suberin. Through the interaction of flavonoids with carbohydrates, lipids, and proteins, the oxidation process 
is inhibited ${ }^{15}$. According to Slimen ${ }^{14}$, the mechanisms behind the antioxidant activities of polyphenols are given in Fig 1.

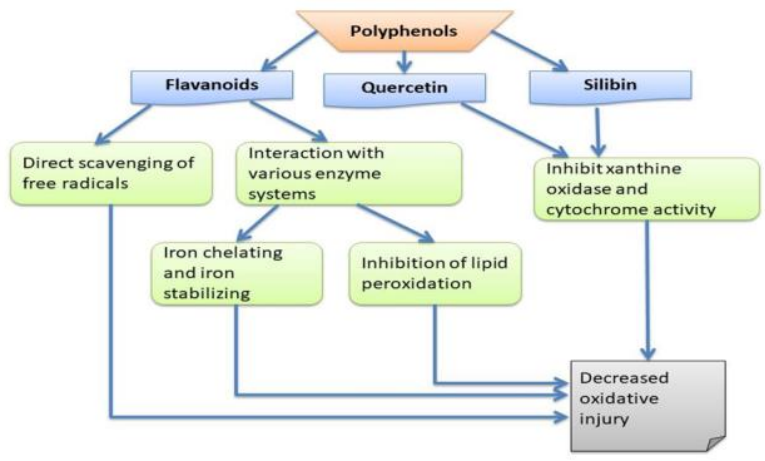

Fig 1. Polyphenols of Opuntia ficus-indica: flavonoids, quercetin and silibin working as antioxidants. (Slimen et al., 2016).

Moreover, Betalains also plays a vital role in antioxidant properties owing to their hydroxyl, imino, and tetrahydropyridine groups. Betalains are pigments present in the vacuole in the form of betalamic acid which condenses and convert into betacyanins (violet color) and betaxanthins (yellow color). In Opuntia ficus-indica these are present in pulp and peel. In the pulp fruit, betanin, betanidin, neobetanin, isobetanin, and indicaxanthin are detected $^{16}$. While in the peel portion, betanin and indicaxanthin are present. The two pigments betanin and indicaxanthin have the ability to donate their electrons that help in the inhibition of lipid peroxidation and heme disintegration. Betanin is more effective in the radical scavenging process rather than indicaxanthin ${ }^{17}$. Betanidin is another potent antioxidant that acts against nitric acid and peroxyl radical and has additive interaction with atocopherol ${ }^{18,19}$. Yahia \& Mondragon-Jacobo ${ }^{7}$ have concluded during their study that tocopherols and carotenoids are not responsible for the antioxidant activity but phenolic compounds, betalains, and vitamin $\mathrm{C}$ are the ones to carry out the antioxidant property. During experimental studies, it has been observed that Opuntia ficus-indica is effective for a decrease in lipid oxidation and an increased amount of antioxidant i.e. reduction in glutathione. This ultimately results in improving the erythrocyte's redox potential. Hence, $500 \mathrm{~g}$ of prickly pear supplement on daily basis is effective for lowering the oxidative stress in a healthy person within two weeks ${ }^{20}$. Similarly, Siriwardhana ${ }^{21}$ also showed that Opuntia ficus- indica (whole fruit) extract has the potential effect as an antioxidant which helped in $60 \%$ decrease in impaired lymphocytes DNA. Hence, the utilization of prickly pear and its products are effective in free radical's reduction that leads to alleviation in the development of chronic ailments.

\section{Anti-inflammatory and Anti-thrombogenic Properties}

The flavonoids present in Opuntia ficus-indica helps in the prevention of inflammation. The mechanism behind this is that they inhibit arachidonic acid metabolism which results in anti-thrombogenic and anti-inflammatory characteristics $^{14}$. Moreover, isorhamnetin glycosides flavonoids namely isorhamnetin-3-0-glucosyl-rhamnoside (IGR) and isorhamnetin- 3-0-glucosyl-rhamnosylrhamnoside (IGRR) regulates anti-inflammatory activities by inhibition of the NFK-B activation and the COX-2 (Cyclooxignase-2) gene expression with suppressing the TNF-a production as well. Antunes-Ricardo ${ }^{22}$ has done the study using alkaline extraction and purification through semi-preparative chromatography of Opuntia ficus-indica and the results suggest that it significantly affects COX-2 and decreased secretion of cytokines and nitric oxide thus exhibiting the anti-inflammatory properties (Fig 2).

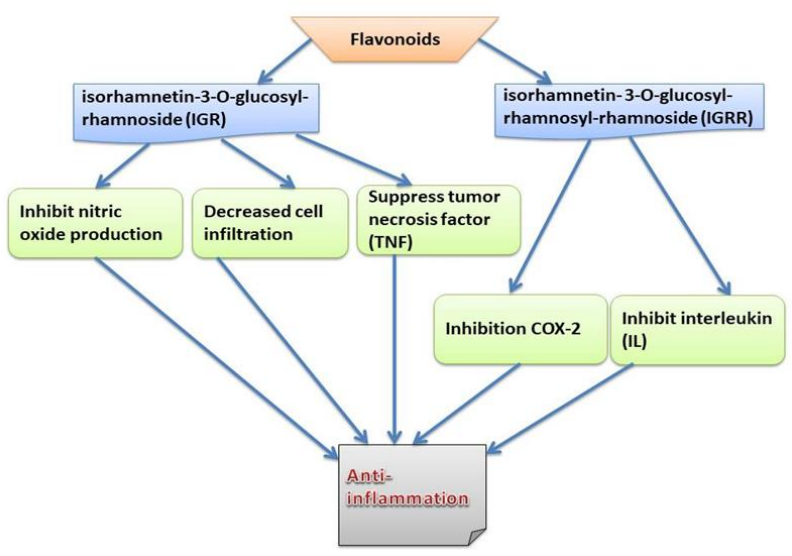

Fig 2. Flavonoids exhibiting anti-inflammation characteristics in the human body. (Antunes-ricardo et al., 2015).

Tesoriere ${ }^{23}$ observed that indicaxanthin from cactus pear (Opuntia ficus-indica L. Mill) fruit prevents eryptosis (programmed cell death of erythrocytes) induced by oxysterols. Eryptotic erythrocytes may contribute to thrombotic complications; as if phosphatidylserine (PS) is exposed to the surface of eryptotic cells may activate 
coagulant enzymes which can cause thrombosis and thrombo-occlusive disease. Further, it will also attach to the endothelial cells and can cause vascular damage. This problem can be prevented by cactus pear (Opuntia ficus-indica) fruit because polyphenol such as betalamic acid and indicaxanthin obtained from it have the reducing potential and amphipathic in nature, interacts with membranes, enters various cells, including erythrocytes and counteracts oxidative damage induced by various events such as the presence of reactive oxygen species (ROS), the release of prostaglandin (PGE2), the opening of prostaglandin dependent calcium channels and exposure of phosphatidylserine (PS). The indicaxanthin of prickly pear fruit in the concentration range of $(1.0-5.0 \mathrm{~mm})$ can eliminate the PS externalization and cell shrinkage.

\section{Anti-carcinogenic and Anti-ulcerogenic Characteristics}

Opuntia ficus-indica also possesses chemo-preventive activity. It was found effective against the inhibition of cancerous cells. Zou ${ }^{24}$ has studied the effect of prickly pear extract on tumor cell growth ${ }^{24}$. He made a comparison of the effects of prickly pear extract and retinoid N-(4-hydroxipernil) retinamide (4-HPR) on cancer cells of cervical, bladder, and ovary. The results showed that there is an obvious increase in cellular apoptosis and inhibition in cancerous cells development (Fig 3).

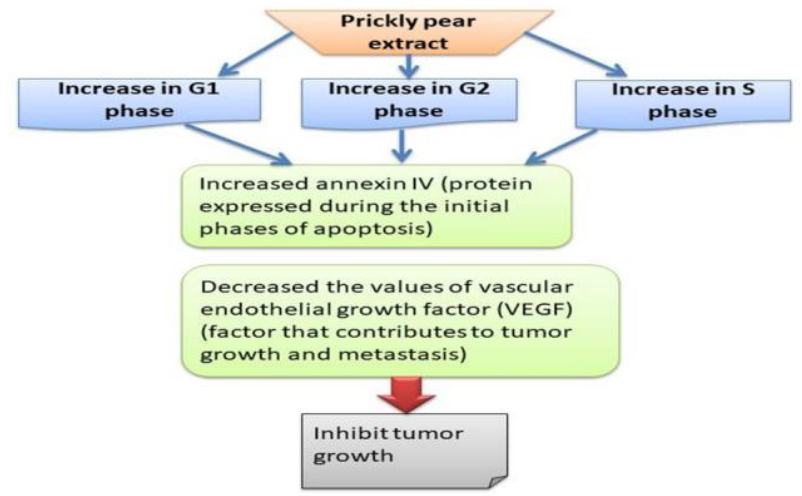

Fig 3. Prickly pear's extract working in tumor growth prevention. (Zou et al., 2005).

Furthermore, betanin extract from Opuntia ficus-indica is also beneficial in terms of cellular apoptosis induction. In myeloid leukemia, betalains impose inhibitory action on the cellular growth ${ }^{25}$. Gastric mucous is a protective layer of gastric cells but if any damage occurs to it, it results in the impairment of cells and many problems such as ulcers, gastritis, and cancer take place. Nonetheless, antioxidants present in the Opuntia ficus-indica have the ability to prevent such problems to arise. Galati26 has studied anti-ulcerogenic effect of Opuntia ficus-indica during a trial on wistar mice. Moreover, the mechanism behind such activity is demonstrated by Jiménez-Aguilar ${ }^{27}$ that is shown in Fig 4.

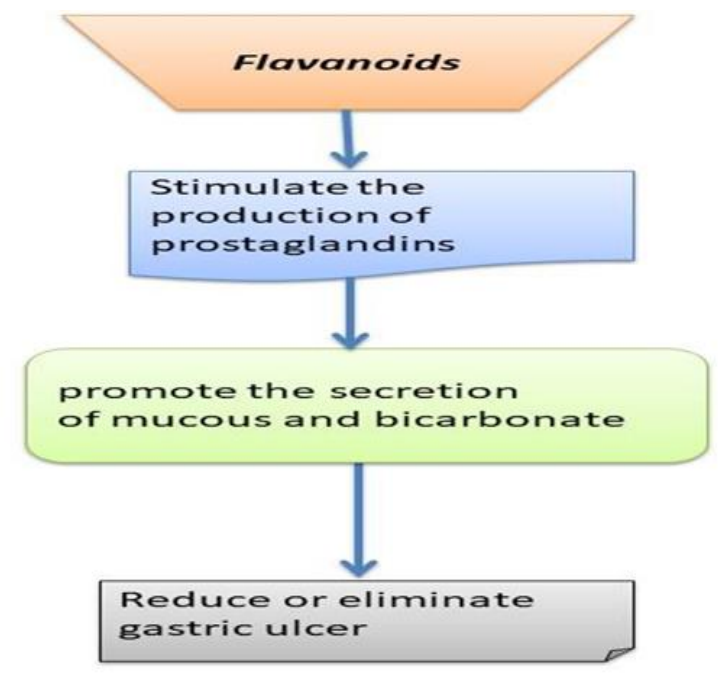

Fig 4. Flavonoids bioactivity in gastric ulcer reduction. (Aguilar et al., 2014).

Another study based on the lyophilized cactus pear fruit juice reported that it has certain constituents that work against the stress-induced gastric lesions particularly betanins and Opuntia ficus-indica var. saboten fruit juice and maltodextrin (OFSM). It was proven that it is effective against the prevention of gastric lesions and gastric mucosal tumor (TNF-a) ${ }^{28}$ (Fig 5).

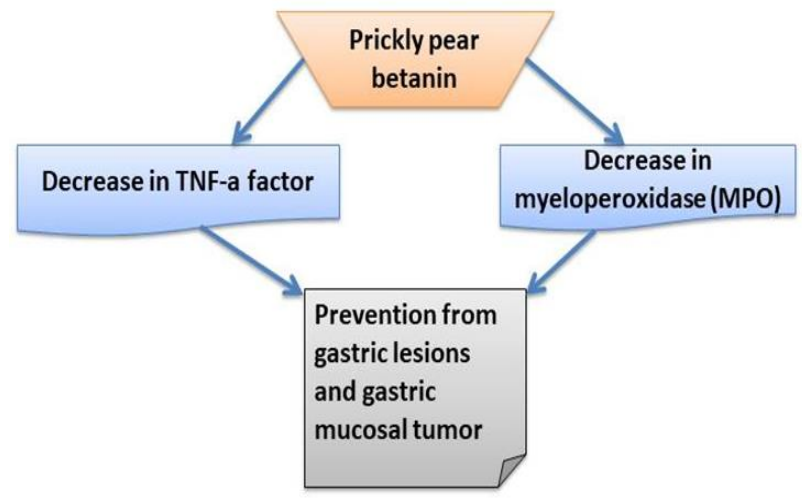

Fig 5. Betanin bioactivity to prevent tumor growth. (Kim et al., 2012). 


\section{Immunomodulatory Activity}

Human body defence system has the ability to fight the disease causing factors and prevent the body, but there are some causalities like an autoimmune disease where the immune system starts to act against the body organs and tissues for example psoriasis, atopic dermatitis, type I diabetes and rheumatoid arthritis. Aires ${ }^{29}$ has conducted the study to find the solution to such a problem and results showed that Opuntia ficus-indica has immunemodulatory effects which are attained by minimizing Jukart T cell multiplication (Fig 6).

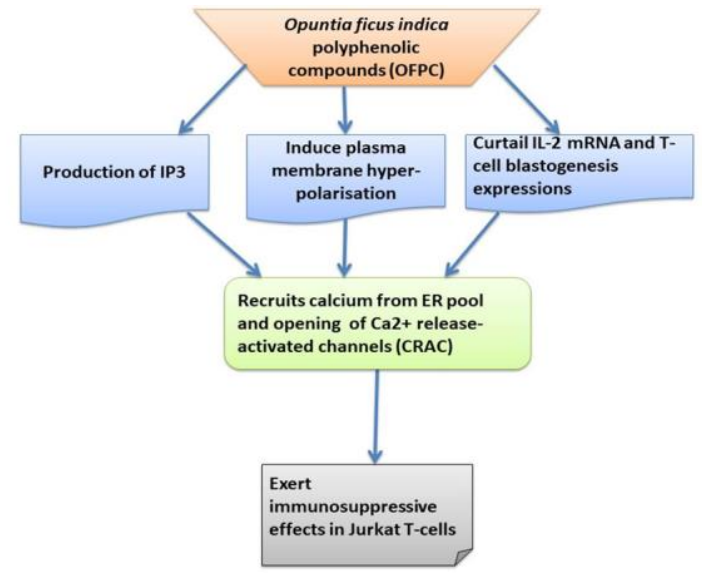

Fig 6. Pathway of polyphenolic compounds of Opuntia ficus-indica acting as immunity boosters. (Aires et al., 2004).

\section{Hepatoprotection}

Liver is a fundamental human body organ as its major role is to detoxify, bile excretion, protein and fat metabolism, and storage of carbohydrates and vitamins. Opuntia ficusindica has proven to be effective for the protection and cure of liver functionality. Galati ${ }^{30}$ has worked on the Opuntia ficus-indica fruit juice for its evaluation of protective working against carbon tetrachloride $\left(\mathrm{CCl}_{4}\right)$ induced hepatotoxicity and found that injury caused $\mathrm{CCl}_{4}$ was cured in $72 \mathrm{hrs}$. Similarly, Djerrou ${ }^{31}$ find out that $\mathrm{CCl}_{4}$ induced hepatotoxicity, can be cured by using aqueous extract of Opuntia ficus-indica. In the results, it was prominent that there was a raised value of aspartate ammonia transferase and alanine ammonia transferase in the groups intoxicated with $\mathrm{CCL}_{4}$ dose which indicate Opuntia ficus-indica aqueous extract's hepatoprotective capability.

\section{Cellular Membrane Protection}

Cladodes of Opuntia ficus-indica are identified for having three carotenoids including $\beta$-carotene, lutein, and $\alpha-$ cryptoxanthin. The highest content of carotenoids was detected in orange color cultivars. While in the case of young cladodes the values fall in 0.047 to $0.077 \mathrm{mg} / 100 \mathrm{~g}$ range and for fruits, the concentration varies between $1.77 \mathrm{mg} / 100 \mathrm{~g}$ and $2.65 \mathrm{mg} / 100 \mathrm{~g}$. The peeling part contains $2.97 \mathrm{mg} / 100 \mathrm{~g}$ of carotenoids ${ }^{32}$. Carotenes and xanthophylls like zeaxanthin, cryptoxanthin, s-carotene, lycopene, and a-carotene are potential singlet oxygen $\left({ }^{1} \mathrm{O}_{2}\right)$ and peroxyl radical quenchers. They scavenge the peroxyl radical and make them stabilized in the form of carbon-centered radical. Moreover, they possess lipophilic properties. Both of these characteristics make them vital for the protection from oxidative impairment of cellular membranes and lipoproteins ${ }^{14}$. Cactus pear was used in traditional medicine for their cicatrisant activity. The cladodes of Opuntia ficus-indica have carbohydrate polymers such as a mixture of mucilage and pectin. The results showed that its cladodes, particularly pectic polysaccharide has the crypto-protection phenomenon by breaking the epithelial cell, increased mucus production, and enhance the number of secretory cells. Ulcer healing is either through regeneration or migration of cells which results in thickening the mucus membrane ${ }^{33}$.

\section{Gastrointestinal Tract}

Recently, cactus cladodes are considered as fiber source for human consumption as its powder contains $43 \%$ fiber including $28.5 \%$ of insoluble fiber. Soluble fibers can impose potential health benefits as they stabilize the intestinal food transit. Moreover, insoluble fibers such as hemicellulose, cellulose, and lignin are beneficial for microbiota, water retention, bile acid absorption, and ionic exchange ${ }^{14}$. Sánchez-Tapia ${ }^{34}$ has checked the prebiotic effect of Nopal (Opuntia ficus-indica) and the results of the study suggest that more consumption of high fat and high sugar food, enhance the chances to get affected with the conditions such as obesity, gut dysbiosis, inflammation, and gut barrier disruption. The reason is the disturbance in the balance of gut microbiota. Nopal is a rich source of dietary fibers, vitamin $\mathrm{C}$, and polyphenols which are effective in the reduction of obesity by 
regulating the gut microbiome and prevent metabolic endotoxemia.

\section{Blood Glucose and Cholesterol}

Opuntia ficus-indica cladodes have soluble fibers including gums, pectin, mucilage, and hemicellulose that help in the lowering of cholesterol level and glycemic index in humans ${ }^{14}$. Polysaccharides, alkaloids, neobetanin, indicaxanthin, and flavonoids extracted from cladodes are capable with special effects of antidiabetic and antiglycation ${ }^{35}$. The redox imbalance is one of the main factors leading to the induction of a genetic basis for diabetes $^{36}$. Berraaouan ${ }^{37}$ suggested that Opuntia ficusindica seed oil have a high amount of polyunsaturated components and antioxidant compounds which are useful against the diabetes mellitus (DM) as it increased the survival rate by $78 \%$ against the diabetes mellitus. According to Milán-Noris ${ }^{38}$ prickly pear is the fruit which is enriched with many phytosterols, betalains, phenolic acids, and flavonoid. Especially, its peel has many bioactive compounds which can be extracted and used as a functional ingredient. His observation proved that the prickly pear peel is enriched with total phytosterols $(65.65 \pm 1.5 \mathrm{mg} / \mathrm{g})$ such as, sitosterol $(76.6 \%)$, campesterol $(19.5 \%)$, and stigmasterol (3.9\%) which show the strong hypocholesterolemic effect. Also, it contains the highest phenolic content which will produce a synergistic effect also.

\section{Benign Prostatic Hypertrophy}

The prostate is a part of the mammalian male reproductive organ which contributes to secretions. It surrounds the bladder and proximal portion of the urethra. Usually, these glandular muscles enlarge and press the urethra which causes hindrance in urination. Opuntia ficus-indica is thought to cure such complications especially the decoction made from the flowers of cactus pear. In North Africa, the flowers of Opuntia combined with barley seeds and corn-silk is used to treat urine obstruction. During a study on clinical trials of its $250 \mathrm{mg}$ capsules by Palevitch ${ }^{39}$, results have shown that patients got relief from the symptoms of obstruction during urination and there was no change in urino-dynamics and kidney functions of the patients. Moreover, flowers of Opuntia ficus-indica are also effective in the cure of benign prostatic hypertrophy ${ }^{40}$.

\section{Wound Healing}

Traditionally, Opuntia ficus-indica cladodes were used to promote wound healing through the formation of a scar. An ointment prepared by using $15 \%$ lyophilized cladodes has shown that it produces more organized tissue reconstruction, fibroblast and fibers will arrange in derma properly and piliferous bulbs will recover in 5 days ${ }^{41}$. For wound healing, it is mandatory to keep the area well hydrated. So, Opuntia ficus-indica oil stimulates the scarring process by the development of epithelium over the granulation muscle and prevents the wound from dehydration as well ${ }^{42}$.

\section{USES AS FOOD}

Opuntia ficus-indica has found its place in a variety of products to utilize in daily routine. This was possible due to its contents that are beneficial for health and also its production is easy and adaptive to the environment. The young tender stem is called "nopalitos" which are used in diverse dishes including salads, soups, snacks, pickled and desserts ${ }^{43}$. Indigenous people utilize the nopal cactus seed extract in tea, juice, jam, or consume as dry or fresh fruits. Moreover, peeled and sliced pads are dried and called as leather britches that help add texture and fibrous material in soups and stews ${ }^{35}$. The cactus pear pulp with effective natural colors is utilized for the preparation of additive-free i.e. artificial color/flavor toppings ${ }^{44}$. It is used in the fortification purpose to make high quality products with high contents of phenolics and antioxidants such as stirred yogurt 45 . The fruit wine is also obtained by the blend of Opuntia ficus-indica and Lantana camara ${ }^{46}$. Furthermore, Cactus pear peel extraction can be successfully used in the substitution of wheat flour biscuits ${ }^{47}$. Its pulp is also utilized in the production of fortified rice milk product ${ }^{48}$. In the Southwestern United States, cactus pear is commonly added to the omelets which are very famous over there.

\section{NUTRACEUTICAL USES}

NeOpuntia prepared by Bio Serae Laboratories is an innovative functional food product that is made of dehydrated leaves of Opuntia ficus-indica containing soluble and insoluble fibers. This product is effective against lipid metabolism disorder and has hypolipidemic characteristics ${ }^{1}$. Furthermore, cactus preparation is also 
proved to be useful for the prevention of alcohol addiction ${ }^{49}$. Traditionally, phytochemical rich products were prepared from Opuntia ficus-indica extracts for herbal medicines ${ }^{35}$. Pharmacopeia, traditional medicine of sub-Sahara is prepared from cactus. Its flowers are effective anti-hemorrhoid medicine while fruits and flowers are antidiarrheal and anti-ulcerogenic mediators. Its cladode sap is the remedy for whooping cough. It involves heating the pads and places it on the chest of the patient which helps in relieving the congestion ${ }^{50}$. Alcoholic extracts of Opuntia ficus-indica is used as an antiviral, hypoglycemic, and anti-inflammatory. Similarly, it has been a part of traditional medicine and curative for various ailments like catarrhal gastritis, hyperlipidemia, edema, burns, wounds, and obesity in different countries ${ }^{51}$. Opuntia ficus-indica cladodes were used by Sicilian folk as cicatrizant (promote the healing through the formation of the scar) ${ }^{41}$. Dehydrated nopal of cactus pear has also served in the nutraceutical market as dietary supplements for having high nutritional value ${ }^{52}$. Not only the extract of cactus pear is helpful in the remedy of high blood sugar level, but also the cooked form plays a significant role in lowering the blood sugar level. It may be due to the presence of high fiber content as pectin absorbs sugar and supports the body in slow release of sugar throughout the day. Similarly, the stem portion of this plant is found to be useful in use for traditional medicine for edema and indigestion ${ }^{53}$. Tea made from the pad has been utilized for the cure of lung diseases ${ }^{54}$. Moreover, it is a traditional cure for various ailments like diuretic action, gastritis, antiulcer activity, arteriosclerosis, antioxidant property, diabetes, cartilage alteration protection, and hyperglycemia ${ }^{55}$. A process known as Chinese medicine is the "moxibustion". In this process, plant material is burned on the skin to cure the infection and irritation. Likewise, the Lakota tribe prepares tea from prickly pear that is found to be helpful in childbirth ${ }^{13}$. Opuntia ficusindica has been utilized as a treatment for the ailments such as bronchial asthma, diabetes, abdominal ache, indigestion and burns in South Korea ${ }^{56}$.

\section{OTHER USES}

Extract of Opuntia ficus-indica cladodes is found to be useful in the reduction of salt stress in the agriculture sector ${ }^{57,58}$. It is also utilized as cattle fodder which imparts quality characteristics in milk. In addition, to enhance the flavor and color of the milk, it also brings nominal changes in the medium and longchain fatty acids in milk profile ${ }^{59}$. Oil extracted from prickly pear seeds are utilized in cosmetics as well 35 . Biogas is an essential energy source in the rural and agricultural areas. Cactus pear cladodes are served for the production of biogas as it has a high potential of biomass production². The cactus pear (both spiny and spineless) was utilized as ruminant feed in Zimbabwe which was imported from South Africa60. The juice prepared by nopal is used as a hair massage which results in soft and shiny hair. Opuntia ficus-indica is utilized in the formation of moisturizers for skin ${ }^{55}$. For many centuries in Mexico, it was utilized in the formation of waterproof paints that are used to paint houses, churches, and marking of property lines. Moreover, it is also useful as a protective barrier against predators. In Central Africa, its juice is proved to be nominal mosquito repellent. It has its ornamental use as well due to its attractive colors and desert landscape. The gum obtained from cactus is usually used for stiffening the clothes. It is also a good source of dye. Additionally, essential oils obtained from its flowers and seeds are consumed as perfumes and oils ${ }^{13}$.

\section{CONCLUSION}

In this modern era, industrialization has made everything possible and we get many alternates of natural products. there are some natural elements have also proven to be effective as well. Global food insecurity, natural resources shortcomings and increase in population are the issues that have already targeted our globe but will become drastic in the future. To avoid such a situation, we need to find the solutions within nature. Opuntia ficus-indica is a natural product that can grow without many natural resources consumption. Moreover, it is proven that it has therapeutic effects for various diseases. Hence, it can become one of the major nutraceutical product in near future owing to its marvelous physical and chemical characteristics.

\section{CONFLICTS OF INTEREST}

None. 


\section{FUNDING SOURCE}

None.

\section{ACKNOWLEDGEMENTS}

None.

\section{LIST OF ABBREVIATIONS}

CAM Crassulacean acid metabolism

$\mathrm{CCl}_{4} \quad$ Carbon tetrachloride

COX-2 Cyclooxignase-2

DM Diabetes mellitus

ha Hectare

hrs Hours

IGR Isorhamnetin-3-O-Glucosyl-Rhamnoside

IGRR Isorhamnetin-3-O-Glucosyl-Rhamnosyl-

Rhamnoside

PGE2 Prostaglandin

PS Phosphatidylserine

ROS Reactive Oxygen Species

\section{REFERENCES}

1. Shetty AA, Rana MK, Preetham SP. Cactus: A medicinal food. J Food Sci Tech. 2012; 49:530-36.

2. Inglese P, Mondragon C, Nefzaoui A, Saenz C. Crop ecology, cultivation and uses of cactus pear. 2017. Food and Agriculture Organization of the United Nations (FAO).

3. Feugang JM, Konarski P, Zou D, Stintzing FC, Zou C. Nutritional and medicinal use of Cactus pear (Opuntia spp.) cladodes and fruits. Frontiers Biosci. 2006; 11:2574-89.

4. Small E, Catling PM. Blossoming treasures of biodiversity 11. Cactus pear (Opuntia ficus-indica)miracle of water conservation. Biodiv. 2004; 5:27-31.

5. Jiménez EA. (2013b). Preámbulo: Importancia de la tuna [Cactus pear importance]. Proceedings of the Second Meeting for the Integral Use of Cactus Pear and Other Cacti and First South American Meeting of the FAO-ICARDA CactusNet, Santiago del Estero, Argentina. 175.

6. Yahia EM, Mondragon-Jacobo C. Nutritional components and antioxidant capacity of ten cultivars and lines of cactus pear fruit (Opuntia spp.). Food Res Int. 2011; 44:11-8.
7. Yahia EM, Sáenz C. Cactus pear (Opuntia species). In Postharvest biology and technology of tropical and subtropical fruits. Woodhead Publishing; 2011; 290331 e.

8. Targa MG, Leguizamon G, Coronel de Renolfi M, Ochoa MJ. Economic feasibility of scozzolatura in traditional and improved orchards of cactus pear in Santiago del Estero, Argentina. Acta Horticulturae. 2013; 995:189-200.

9. Piga A. Cactus Pear: A fruit of nutraceutical and functional importance. J Professional Assoc Cactus Dev. 2004; 9-22.

10. Brinker FND. Prickly pear as food and medicine. J Diet Suppl. 2009; 6:362-76.

11. Kuti J. Antioxidant compounds from four Opuntia cactus pear fruit varieties. Food Chem. 2004; 85:52733.

12. Stintzing $F$, Herbach $\mathrm{K}$, Moßhammer M, Carle $\mathrm{R}, \mathrm{Yi}$ W, Sellappan $S$, et al. Color, betalain pattern, and antioxidant properties of cactus pear (Opuntia sp.) clones. J Agric Food Chem. 2005; 53:442-51.

13. Saleem M, Kim HJ, Han CK, Jin C, Lee YS. Secondary metabolites from Opuntia ficus-indica var. Saboten. Phytochemistry. 2006; 67:1390-4.

14. Slimen IB, Najar T, Abderrabba M. Opuntia ficusindica as a source of bioactive and nutritional phytochemicals. J Food Nutr Sci. 2016; 4:162-69.

15. Jakobek L. Interactions of polyphenols with carbohydrates, lipids and proteins. Food Chem. 2015; 175:556-67.

16. Yeddes N, Cherif JK, Guyot S, Sotin H, Ayadi MT. Comparative study of antioxidant power, polyphenols, flavonoids and betacyanins of the peel and pulp of three Tunisian Opuntia forms. Antioxidants. 2013; 2:37-51.

17. Gandia-Herrero F, Escribano J, Garcia-Carmona F. Purification and antiradical properties of the structural unit of betalains. J Nat Prod. 2012; 75:1030-6.

18. Taira J, Tsuchida E, Katoh MC, Uehara M, Ogi T. Antioxidant capacity of betacyanins as radical scavengers for peroxyl radical and nitric oxide. Food Chem. 2015; 166:531-6.

19. Tesoriere L, Allegra M, Gentile C, Livrea MA. Betacyanins as phenol antioxidants, Chemistry and mechanistic aspects of the lipoperoxyl radicalscavenging activity in solution and liposomes. Free Radic Res. 2009; 43:706-17. 
20. Tesoriere L, Butera D, Pintaudi AM, Allegra M, Livrea MA. Supplementation with cactus pear (Opuntia ficusindica) fruit decreases oxidative stress in healthy humans: A comparative study with vitamin $\mathrm{C}$. Am J Clin Nutr. 2004; 80:391-5.

21. Siriwardhana N, Shahidi F, Jeon YJ. Potential antioxidant effects of cactus pear fruit (Opuntia ficusindica) extract on radical scavenging and DNA damage reduction in human peripheral lymphocytes. J Food Lipids. 2006; 13:445-58.

22. Antunes-Ricardo M, Gutiérrez-Uribe JA, LópezPacheco F, Alvarez MM, Serna-Saldivar SO. In vivo anti-inflammatory effects of isorhamnetin glycosides isolated from Opuntia ficus-indica (L.) Mill cladodes. Indus Crops Prod. 2015; 76:803-8.

23. Tesoriere L, Attanzio A, Allegra M, Livrea MA. Dietary indicaxanthin from cactus pear (Opuntia ficus-indica L. Mill) fruit prevents eryptosis induced by oxysterols in a hypercholesterolaemia-relevant proportion and adhesion of human erythrocytes to endothelial cell layers. Br J Nutr. 2015; 114:368-75.

24. Zou DM, Brewer M, Garcia F. Cactus pear: A natural product in cancer chemoprevention. Nutr J. 2005; 4:25-37.

25. Sreekanth D, Arunasree MK, Roy KR, Chandramohan T, Reddy GV, Reddanna P. Betanin: A betacyanin pigment purified from fruits of Opuntia ficus-indica induces apoptosis in human chronic myeloid leukemia Cell line-K562. Phytomedicine. 2007; 14:739-46.

26. Galati EM, Mondello MR, Giuffrida D. Chemical characterization and biological effects of Sicilian Opuntia ficus indica (L.) Mill. Fruit juice: Antioxidant and antiulcerogenic activity. J Agric Food Chem. 2003; 51:4903-8.

27. Jiménez-Aguilar DM, Mújica-Paz H, Welti-Chanes J. Phytochemical characterization of prickly pear (Opuntia spp.) and of its nutritional and functional properties: A review. Curr Nutr Food Sci. 2014; 10:5769.

28. Kim SH, Jeon BJ, Kim DH, Kim TI, Lee HK, Han DS. Prickly pear cactus (Opuntia ficus indica var. saboten) protects against stress-induced acute gastric lesions in rats. J Med Food. 2012; 15:968-73.

29. Aires V, Adote S, Hichami A, Moutairou K, Boustani $\mathrm{EE}$, Khan NA. Modulation of intracellular calcium concentrations and $\mathrm{T}$ cell activation by prickly pear polyphenols. Mol Cell Biochem. 2004; 260:103-10.
30. Galati EM, Mondello MR, Lauriano ER, Taviano MF, Galluzzo M, Miceli N. Opuntia ficus-indica (L.) Mill. Fruit juice protects liver from carbon tetrachloride induced injury. Phytother Res. 2005; 19:796-800.

31. Djerrou Z, Maameri Z, Halmi S, Djaalab H, Riachi F, Benmaiza $L$, et al. Hepatoprotective effect of Opuntia ficus-indica aqueous extract against carbon tetrachloride-induced toxicity in rats. J Biol Sci. 2015; 15:36-41.

32. Chougui $\mathrm{N}$, Louaileche $\mathrm{H}$, Mohedeb S, Mouloudj $\mathrm{Y}$, Hammoui Y, Tamendjari A. Physico-chemical characterization and antioxidant activity of some Opuntia ficus-indica varieties grown in North Algeria. Afr J Biotechnol. 2013; 12:299-307.

33. Galati EM, Pergolizzi S, Miceli N, Monforte MT, Tripodo MM. Study on the increment of the production of gastric mucus in rats treated with Opuntia ficus indica (L.) Mill. cladodes. J Ethnopharmacol. 2002; 83:229-33.

34. Sánchez-Tapia M, Aguilar-López M, Pérez-Cruz C, Pichardo-Ontiveros E, Wang M, Donovan SM. Nopal (Opuntia ficus indica) protects from metabolic endotoxemia by modifying gut microbiota in obese rats fed high fat/sucrose diet. Sci Rep. 2017; 7:1-16.

35. El-Mostafa K, El-Kharrassi $\mathrm{Y}$, Badreddine A, Andreoletti P, Vamecq J, El-Kebbaj MHS et al. Nopal cactus (Opuntia ficus-indica) as a source of bioactive compounds for nutrition, health and disease. Mol. 2014; 19: 14879-901.

36. Droge W. Free radicals in the physiological control of cell function. Physiol Rev. 2002; 82:47-95.

37. Berraaouan A, Abderrahim $Z$, Hassane $M$, Abdelkhaleq L, Mohammed A, Mohamed, B. Evaluation of protective effect of cactus pear seed oil Opuntia ficus-indica (L.) Mill. against alloxan-induced diabetes in mice. Asian Pac J Trop Med. 2015; 8:5327.

38. Milán-Noris KA, Chavez-Santoscoy A, OlmosNakamura R, Gutiérrez-Uribe AA, Serna-Saldívar OS. An extract from prickly pear peel (Opuntia ficusindica) affects cholesterol excretion and hepatic cholesterol levels in hamsters fed hyperlipidemic diets. Curr Bioact Compd. 2016; 12:10-16.

39. Palevitch D, Earon G, Levin I. Treatment of benign prostatic hypertrophy with Opuntia ficus-indica (L.) Mil. J Herbs Spices Med Plants. 1993; 2:45-9. 
40. British Herbal Phannacopeia (BHP). The British Herbal Medicine Association, West York, England. 255 p. 1983.

41. Galati EM, Mondello MR, Monforte MT, Galluzzo M, Miceli N, Tripodo MM. Effect of Opuntia ficus-indica (L.) Mill. Cladodes in the wound-healing process. J Prof Asso Cactus Develop. 2003; 5:1-16.

42. Khémiri I, Hédi BE, Zouaoui NS, Gdara NB, Bitri L. The antimicrobial and wound healing potential of Opuntia ficus indica L. extracted oil from Tunisia. Evid Based Comp Altern Med. 2019.

43. Saenz-Hernandez C, Corrales-García J, AquinoPerez G. Nopalitos, mucilage, fiber and cochineal. In: Nobel, P. (Ed), Cacti, Univ, of California Press, Ltd London, England, 2002; p. 211-34.

44. Morales M, Saenz C, Robert P. Bioactive compounds in toppings from colored cactus pear cultivated in Chile. Acta Horticulturae. 2009; 811:127-30.

45. Hallim AM, Rabie A, El-Shewey MA, Abdel-Ghany AS. Evaluation of physico-chemical properties and antioxidant activity of stirred yoghurt fortified with pomegranate and cactus pear juices. Zagazig J Agric Res. 2019; 46:1995-2008.

46. Tsegay ZT, Gebremedhin KM. Physicochemical and sensory properties of wine produced from blended cactus pear (Opuntia ficus-indica) and Lantana camara (L. camara) fruits. J Food Qua. 2019.

47. El-Shahat MS, Rabie MA, Ragab M, Siliha HI. Changes on physicochemical and rheological properties of biscuits substituted with the peel and alcohol-insoluble solids (AIS) from cactus pear (Opuntia ficus-indica). J Food Sci Technol. 2019; 56:3635-45.

48. El-Sayed H, Ramadan MF. Production of probioticfermented rice milk beverage fortified with cactus pear and physalis pulp. Zagazig J Agric Res. 2020; 47:165-77.

49. Tomczyk M, Koncic MZ, Chrostek L. Physiotherapy of Alcoholism. Nat Prod Commun. 2012; 7:273-80.

50. Alimi H, Hfaiedh N, Bouoni Z, Hfaiedh M, Sakly M, Zourgui $\mathrm{L}$, et al. Antioxidant and antiulcerogenic activities of Opuntia ficus indica ( $F$. inermis) root extract in rats. Phytomed. 2010; 17:1120-6.
51. Kaur M, Kaur A, Sharma R. Pharmacological actions of Opuntia ficus indica: A Review. J Appl Pharm Sci. 2012; 2:1.

52. Prakash D, Sharma G. (Eds.). Phytochemicals of nutraceutical importance. 2014; CABI.

53. Park EH, Chun MJ. Wound healing activity of Opuntia ficus-indica. Fitoterapia. 2000; 72:165-7.

54. Foster S, Duke JA. Field guide to medicinal plants and herbs of Eastern and Central North America. 2nd ed, Boston: Houghton Mifflin Company, 2000.

55. Damasceno GAB, Silva RMAC, Fernandes JM, Ostrosky EA, Langassner SMZ, Ferrari M. Use of Opuntia ficus-indica (L.) Mill extracts from Brazilian Caatinga as an alternative of natural moisturizer in cosmetic formulations. Braz J Pharm Sci. 2016; 52:450-70.

56. Kim JH, Park SM, Ha HJ. Opuntia ficusindica attenuates neuronal injury in in vitro and in vivo models of cerebral ischemia. J Ethnopharmacol. 2006; 104:257-62.

57. Sáenz C, Berger H, Félix AR, Galletti L, García JC, Sepúlveda E, et al. Agro-industrial utilization of cactus pear. Food and Agriculture Organization of the United Nations. 2013.

58. Rai A, Cherif A, Cruz C, Nabti E. Extracts from seaweeds and Opuntia ficus-indica cladodes enhance diazotrophic-PGPR halotolerance, their enzymatic potential, and their impact on wheat germination under salt stress. Pedosphere. 2017.

59. Oliveira VSD, Ferreira MDA, Guim A, Modesto EC, Arnaud BL, Silva FMD. Effects of replacing corn and tifton hay with forage cactus on milk production and composition of lactating dairy cows. Revista Brasileira de Zootecnia. 2007; 36:928-35.

60. Makumbe MT. A review of the distribution, use and potential of cactus pear (Opuntia ficus-indica (L.) Mill. as ruminant feed in Zimbabwe. Improved utilization of cactus pear for food, feed, soil and water conservation and other products in Africa. 2010; 3643. 